Full length article

\title{
Crushing behavior of a thin-walled circular tube with internal gradient grooves fabricated by SLM 3D printing
}

\author{
Zhe Yang ${ }^{\mathrm{a}, 1}$, Yangyang Yu ${ }^{\mathrm{b}, 1}$, Yanpeng $\mathrm{Wei}^{\mathrm{a}, *}$, Chenguang Huang ${ }^{\mathrm{a}}$ \\ ${ }^{a}$ Key Laboratory for Mechanics in Fluid Solid Coupling Systems, Institute of Mechanics, Chinese Academy of Sciences, Beijing 100190, China \\ b CRRC Qingdao Sifang Locomotive \& Rolling Stock Co.,Ltd., Qingdao 266111, China
}

\section{A R T I C L E I N F O}

\section{Keywords:}

Selective laser melting (SLM)

3D printing

Thin-walled tube

Internal defects

Energy absorption

\begin{abstract}
A B S T R A C T
Selective laser melting (SLM) is a mature method in the fabrication of structures bearing static loading and small strains; however, structures experiencing large deformation under impact loading remains an issue. In this paper, the author fabricates a 316L stainless steel thin-walled circular tube with preset internal circumferential rectangular groove defects using the SLM method. MTS compression and Split Hopkinson Pressure Bar tests are performed to judge the material behavior of SLM printed 316L stainless steel, and Johnson-Cook constitutive model parameters are fitted from the results. The crushing behavior of the SLM printed tube is studied experimentally and numerically via the drop hammer test and the finite element analysis. There are two stages of the crushing process of the tube as the results show: the buckling stage and the splitting stage. The internal grooves have effects on controlling the initial buckling position and fracture position during the buckling stage. The double buckling-splitting crushing mode in one simple structure, provides a new energy absorption approach for engineering application.
\end{abstract}

\section{Introduction}

3D printing, as a rapidly emerging additive manufacturing process, can fabricate complex structural components efficiently with a high precision and low cost [1,2]. For conventional metals, such as 316L stainless steel and Ti alloy, selective laser melting (SLM) is recognized as the best method to fabricate large-size arbitrary structures among the numerous 3D printing technologies [2,3]. As the printed structure is often used as a "support component", the microstructure, structural strength and fatigue behavior have recently received a great deal of attention [4-6]. As a realization of the advantage of fabrication by SLM 3D printing method, design and optimization for light weight, porous or lattice structures have received a lot of attention recently [6-9]. Challis et al. [6] developed two types of Ti6Al4V open-cell structures by topology optimization and gyroid labyrinth design, fabrication was done by SLM method. The stiffness and specific strength of the two types of structures have been compared using experimental and numerical methods. Yan et al. [7] studied the manufacturability and performance of stainless steel cellular lattice structures with different volume fraction and fabrication orientations, compression tests show that structural yield strength and Young's moduli have increasing trend with the volume fraction.
Further, in large deformation area, many authors studied the crushing behavior of SLM printed lattice structures with different cell types and sizes [10-14]. Mckown et al. [10] performed quasi-static compression tests and blast tests for the metallic lattice structures with different cells, failure buckling modes of different structures and strain rate sensitivity were observed. Smith et al. [13] developed finite element models to predict the compressive behavior of the lattice structures, the numerical model can predict the stress-strain curve and crushing mode well with the experimental results. Structural optimization has been done numerically and theoretically, showing the stiffness, yield strength and energy absorption can be improved by reducing the unit cell aspect ratio. Yang et al. [15] fabricated brass tubes with and without origami patterns using 3D printing and the origami patterns can significantly reduce the initial peak force, while the energy absorption capacity could be improved or maintained. However, the high strain rate deformation and fracture behaviors when bearing impact loading of SLM printed thin-walled structures, such as thinwalled circular tubes, lack systematic experimental and numerical results.

Thin-walled metal tube may be the most commonly used "impact energy-absorbing component" in engineering applications. There are many findings and progress in this area over the past decades, as

\footnotetext{
* Corresponding author.

E-mail address: weiyanpeng@imech.ac.cn (Y. Wei).

${ }^{1}$ These two authors contributed equally to this work and should be considered co-first authors.
} 
described in detail in the review articles and books [16-19]. Thinwalled metal tubes can deform through different modes according to different loading and boundary conditions. For axial loading conditions, the tubes mainly deform through axial crushing mode [20-26], inversion mode [27-33] and splitting mode [34-39]. Axial crushing mode shows high specific energy absorption, high stroke efficiency and stable progressive buckling behavior, becoming one of the most efficient and widely used modes. A shaped die or clamp is often needed in inversion and splitting modes to initiate and retain the process. These two modes can respond relatively flat force-displacement curves, but demands rigorous external loading conditions. For lateral loading conditions, the deformation modes mainly include lateral compression mode [40-45] and lateral indentation mode [45-48]. The lateral modes have low compression displacement and smooth force-deflection responses, showing advantage to use in relatively narrow energyabsorbing space than the axial crushing mode.

When designing and evaluating an energy-absorbing tube for a specific loading condition, the tube geometry and material properties must be carefully considered. In terms of geometry, various defects and/or ribs are often preset along the tube to adjust the energyabsorbing process $[49,50]$. Wei et al. [51] systematically studied the axial buckling behavior of thin-walled circular tubes with preset gradient rectangular grooves, the crushing force process, buckling position and sequence can be proactively predicted and regulated, free-fall impact experiments show that gradient grooved tube (GGT) has a better stability than perfect tube when used as an energy absorber to protect the graphite in nuclear reactor from slender control rod impact. Compared with machining the defects on tube via milling, turning, or welding by a secondary process, it is more suitable to print the tube by SLM 3D printing to improve the accuracy and simplify the fabrication procedure. Furthermore, preset internal defects inside the tube wall can be easily fabricated by 3D printing while it is quite difficult for the conventional processing technology. The defects preset inside the tube wall are expected to function as the grooves outside the tube wall as Wei et al.'s work [51], at the same time the internal defects would not affect the original outward appearance of the structure, benefiting to the assembly and application of the structure.

However, in terms of materials, the low toughness of printed metals could negatively affect the energy-absorbing process. Researchers have found that the yield strength of SLM printed 316L stainless steel is significantly improved but that the elongation (ductility) is obviously decreased compared with the cast or wrought fabrication methods $[52,53]$. The static stretch limit for SLM printed 316L stainless steel $(10-27 \%)$ is far less than the wrought $316 \mathrm{~L}$ stainless steel $(40-50 \%)$. When the SLM printed structure bears axial loading, the brittle character of the material tends to induce fracture of the structure. For example, the SLM printed TiAl6V4 lattice structure fractures when the macroscopic strain reaches $20 \%$ due to the low ductility $(\sim 10 \%)$ of the material [14]. For the buckling mode of the SLM printed thinwalled tube, the plastic hinges may not bend into a complete fold before it fractures because of the material brittleness. Thus, the energy absorbing capacity cannot be predicted by the traditional theory based on the formation of plastic hinges, such as Alexander's model [54]. In this case, numerical prediction of the crushing behavior appears to be particularly important for such SLM printed structures. Meanwhile, when bearing dynamic loads, the strain rate that the structure experienced has a temporal-spatial distribution, that is, the forcedisplacement curve will be more complicated if the tube is printed using strain-rate sensitive materials. Thus, the material constitutive model and parameters, which directly determine the buckling process of printed tubes, need to be carefully considered in numerical models to simulate the effects of strain rate hardening, strain hardening and material failure. However, there are few literature reports regarding the high strain rate properties of SLM printed 316L stainless steel.

In this work, a thin-walled circular tube with preset internal circumferential rectangular grooves are designed and fabricated by

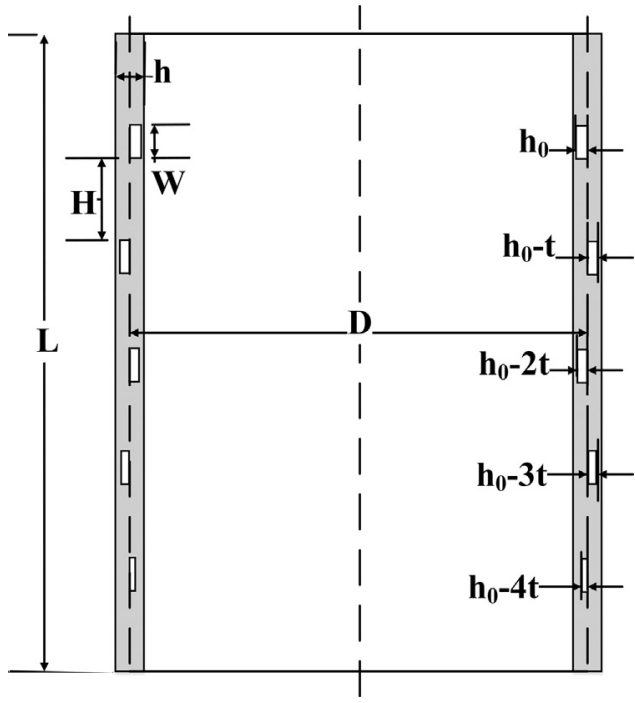

Fig. 1. Design diagram of the SLM printed tube with internal circumferential grooves.

SLM 3D printing with 316L stainless steel powder. The impact crushing behavior of the tube is experimentally studied using a 180$\mathrm{kg}$ drop hammer at a speed of $7.4 \mathrm{~m} / \mathrm{s}$. The tube showed a good energyabsorbing capacity with a relative stable crushing force curve under axial dynamic loading, buckling-splitting behavior has been observed in the process. Finite element analysis is performed to predict and evaluate the buckling-splitting behavior. The Johnson-Cook constitutive model [55] is used to reflect the effect of strain rate hardening, strain hardening and material failure of the SLM printed stainless steel. Good agreement was found regarding the energy-absorbing capacity, crushing force curve, and buckling-splitting behavior between the experimental and numerical results.

\section{Design and preparation of the specimen}

Fig. 1 shows the design diagram of a thin-walled circular tube with internal circumferential rectangular grooves. The geometric parameters for the tube are: tube length $L$, Diameter $D$, and wall thickness $h$. The defect parameters are as follows: $W$ is the width of the grooves, $H$ is the length between grooves, $h_{0}$ is the initial depth of the groove, and $t$ is the depth variation parameter.

The external dimensions of the thin-walled tube that we chose are $L=70 \mathrm{~mm}, D=52 \mathrm{~mm}, h=2 \mathrm{~mm}$. The geometry and arrangement of the grooves are designed in accordance with three non-dimensional parameters [51]: the non-dimensional initial depth of the internal groove $\left(h_{0} / h\right)$ controls the local buckling stability of the first groove region; the non-dimensional width of the internal groove $\left(\mathrm{W} /\left(\mathrm{h}_{0}+\mathrm{h}\right)\right)$ determines the folding space to avoid squeezing of bending beams each other; and the non-dimensional half wavelength $((\mathrm{H}+\mathrm{W}-\mathrm{h}) / \sqrt{\mathrm{Dh}})$ is the ratio of the artificial half wavelength to the inherent half wavelength, where $\sqrt{D h}$ represents the inherent half wavelength [54,56], and $H+W$ $h$ is the artificial half wavelength that we hope to control during the buckling process.

The non-dimensional defect parameters in this experiment are chosen as $h_{0} / h=0.3, \mathrm{~W} /\left(\mathrm{h}_{0}+\mathrm{h}\right)=\frac{\pi}{2},(\mathrm{H}+\mathrm{W}-\mathrm{h}) / \sqrt{\mathrm{Dh}}=1$ to maintain the initial buckling stability and regulate the crushing mode and process. So, being in accordance with the tube geometry and non-dimensional defect parameters, the defect parameters are $W=4 \mathrm{~mm}, H=8 \mathrm{~mm}$, $h_{0}=0.6 \mathrm{~mm}$. The depth variation $t$ is set as $0.1 \mathrm{~mm}$, so the groove depths in the two ends are $0.6 \mathrm{~mm}$ and $0.1 \mathrm{~mm}$. As shown in Fig. 1, there are five internal grooves along the tube in this model.

To study the quasi-static and dynamic material behavior of SLM printed $316 \mathrm{~L}$ stainless steel, $\varphi 6 \mathrm{~mm}^{*} 10 \mathrm{~mm}$ and $\varphi 10 \mathrm{~mm}^{*} 10 \mathrm{~mm}$ cylindrical specimens are fabricated using the same process and 
Table 1

The chemical composition of 316L stainless steel powder.

\begin{tabular}{|c|c|c|c|c|c|c|c|c|c|}
\hline Component & $\mathrm{Fe}$ & $\mathrm{Cr}$ & $\mathrm{Ni}$ & Mo & $\mathrm{Mn}$ & $\mathrm{Si}$ & $\mathrm{P}$ & $\mathrm{C}$ & $\mathrm{S}$ \\
\hline Indicative value (\%) & Balance & $16.5-18.5$ & $10.1-13.0$ & $2.0-2.5$ & $0-2.0$ & $0-1.0$ & $0-0.045$ & $0-0.03$ & $0-0.03$ \\
\hline
\end{tabular}
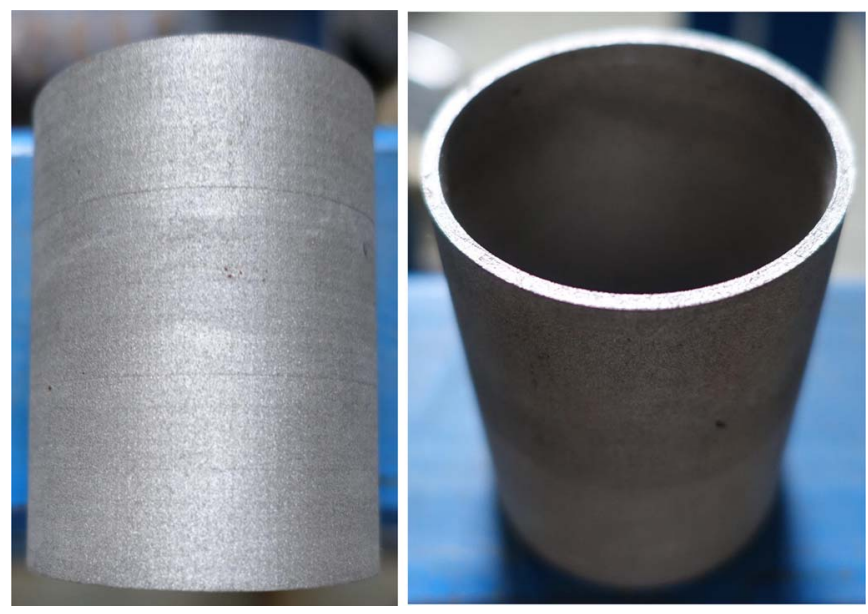

Fig. 2. SLM printed 316L thin-walled circular tube with internal grooves.

parameters with the tube. All of the specimens are printed using Mlabcusing-R equipment manufactured by Concept Laser Corporation. The primary characteristics of this equipment are as follows:

Laser power: $100 \mathrm{~W}$

Laser spot size: $40 \mu \mathrm{m}$

Scanning speed: up to $7 \mathrm{~m} / \mathrm{s}$

Layer thickness: $15-50 \mu \mathrm{m}$

Powder size: $45 \pm 10 \mu \mathrm{m}$

The chemical composition of 316L powder is shown in Table 1 . The SLM printed thin-walled circular tube specimen is shown in Fig. 2. The integrity of the printed material is higher than $99 \%$, and the mass of the tube is approximately $180 \mathrm{~g}$.

\section{Material behavior}

The quasi-static and dynamic compression property of SLM printed specimens are measured using MTS 810 Material Test System and Split Hopkinson Pressure Bar (SHPB) respectively (Fig. 3). The cylindrical specimen size for quasi-static test is $\varphi 6 \mathrm{~mm}^{*} 10 \mathrm{~mm}$, and for dynamic test is $\varphi 10 \mathrm{~mm}^{*} 10 \mathrm{~mm}$. The quasi-static compression test is performed under the compression speed $0.01 \mathrm{~mm} / \mathrm{s}$, corresponding strain rate is $0.001 \mathrm{~s}^{-1}$, and the true quasi-static stress-strain is shown in Fig. 4. The input bar and transmission bar of the SHPB are both composed of AISI 1045 steel with a $16-\mathrm{mm}$-diameter and $1200-\mathrm{mm}$-length. The projectile has a $16-\mathrm{mm}$-diameter and $300-\mathrm{mm}$-length, the velocity of the projectile is about $21 \mathrm{~m} / \mathrm{s}$, which is precisely controlled by a gas gun (chosen gas pressure is about $0.3 \mathrm{MPa}$ ) to obtain an average strain rate of approximately $600 \mathrm{~s}^{-1}$, which corresponds with values that materials could experience in the buckling process. All of the experiments were performed at room temperature $300 \mathrm{~K}$.

An empirical Johnson-Cook constitutive model [55] is used here to reflect the strain hardening and strain rate hardening effects of metal materials. The high temperature soften effect is not considered here, so the plastic flow stress can be simplified as Eq. (1):

$\sigma_{e q}=\left(A+B \varepsilon^{n}\right)\left(1+C \ln \dot{\varepsilon}^{*}\right)$

where $\varepsilon$ is the equivalent plastic strain and $\dot{\varepsilon}^{*}=\dot{\varepsilon} / \dot{\varepsilon}_{0}$ is the dimensionless plastic strain rate for $\dot{\varepsilon}_{0}=1 \mathrm{~s}^{-1}$. The expression in the first bracket gives the stress as a function of strain for strain rate $\dot{\varepsilon}^{*}=1$. The expression in the second bracket represents the effects of the strain rate.

The value of the constitutive parameters $A, B, n$ and $C$ are derived from the fitting results of the quasi-static and dynamic stress-strain curves, as shown in Fig. 4, where $A=380 \mathrm{MPa}, B=825 \mathrm{MPa}, n=0.726$ and $C=0.115$.

\section{Experimental setup}

The drop hammer experiment was performed using a 180-kg mass block, as shown in Fig. 5. The hammer was dropped from a height of $2.8 \mathrm{~m}$; via gravity acceleration, it reached a velocity $V \approx 7.4 \mathrm{~m} / \mathrm{s}$ before impacting the tube specimen. The buckling process was captured by a high-speed camera with the mode of $20,000 \mathrm{fps}$ at a resolution of $320 \times 768$ pixels. Two 200 -W LEDs were used as the light source to supply adequate luminous flux for the high-speed camera. The drop hammer displacement and velocity were obtained by the two-dimensional digital image correlation (2D DIC) method using the images captured by the high-speed camera. A rectangular speckled band on the drop hammer was set as tracing area, as shown in Fig. 6, on a plane parallel to the CCD sensor during the crushing process. The rectangle length $(100 \mathrm{~mm})$ was used as the reference to calibrate the real distance in the images. The transient crushing force is measured by a pressure sensor assembly located and fixed at the bottom of the back plate. The piezoelectric coefficient of pressure sensor was $30449 \mathrm{~N} / \mathrm{V}$, as calibrated by a material testing system.

As shown in Fig. 5, the bottom of the tube is inserted into the slot of the back plate with $3 \mathrm{~mm}$, the back plate is fixed with the force sensor through threaded connection. The force sensor is inserted into the groove of the "back plate of force sensor", which is fixed with the drop hammer frame with bolts.

\section{Numerical model}

A finite element analysis model has been established by Abaqus/ Explicit code to simulate the crushing behavior of the SLM printed 316L stainless steel tube. As shown in Fig. 7, four parts are defined in this model: the impactor, the thin-walled tube with internal grooves, the base and the rigid wall. The impactor and the rigid wall are set as analytical rigid body, the impactor has a mass of $180 \mathrm{~kg}$ and initial axial velocity of $7.4 \mathrm{~m} / \mathrm{s}$, with all other freedoms fixed. The rigid wall is fixed for all degrees of freedom to model the ground. The tube-base and base-rigid wall contacts are both set as "tied".

The tube and base are both discretized with 8 node hexahedral elements. The tube is modeled with approximately 200 elements in the longitudinal direction, 80 elements in the circumferential direction and approximately 6 elements through the shell thickness. The base - rigid wall and the tube - base contacts are set as "tied", while all of the others are set as "general contact". The base is modeled as an elastic body to acquire an accurate reaction force, which represents the crushing force of the tube. The plastic behavior of the tube is simulated by JohnsonCook constitutive model, the model parameters A, B, n and C are the fitted parameters in Section 2.

To simulate the fracture characteristics during the crushing process, the Johnson-Cook damage initiation model is chosen; this model considers the strain, strain rate and temperature effects on the damage initiation strain, which is expressed as Eq. (2) [55]. When equivalent plastic strain reaches the damage initiation plastic strain $\varepsilon_{0}^{p l}$, the stressstrain curve reaches its peak and after which the material stiffness 
(a)

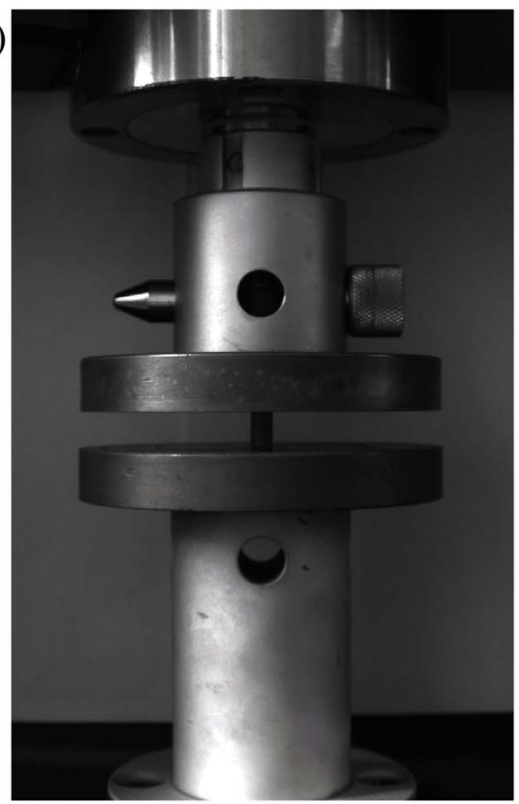

(c)

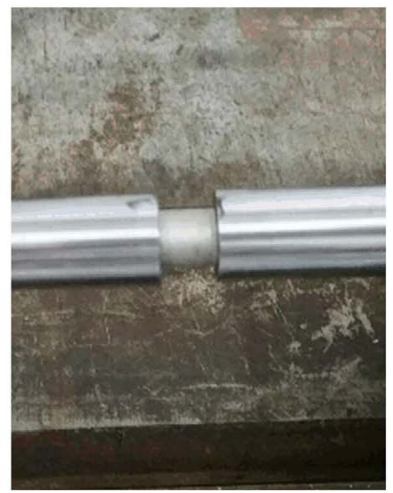

(b)

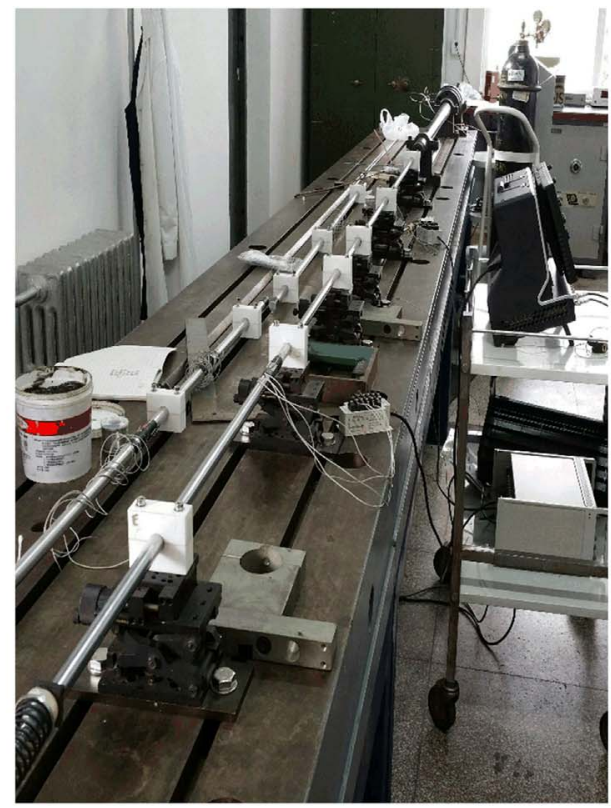

(d)

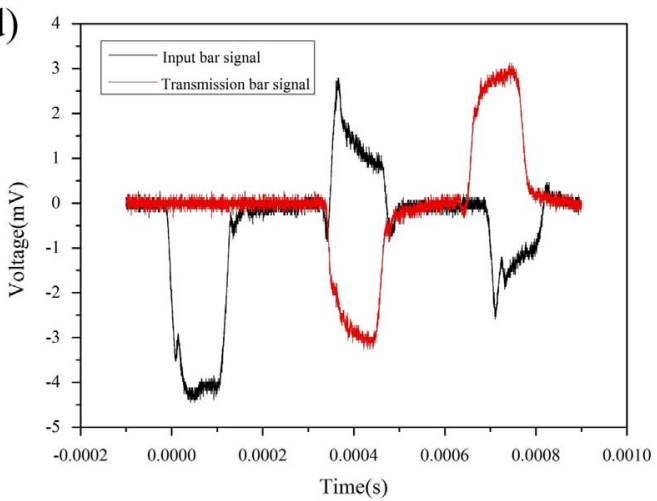

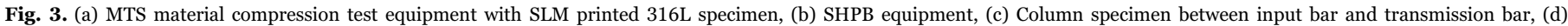
Original Voltage-time signal for SLM printed 316L specimen from SHPB test.

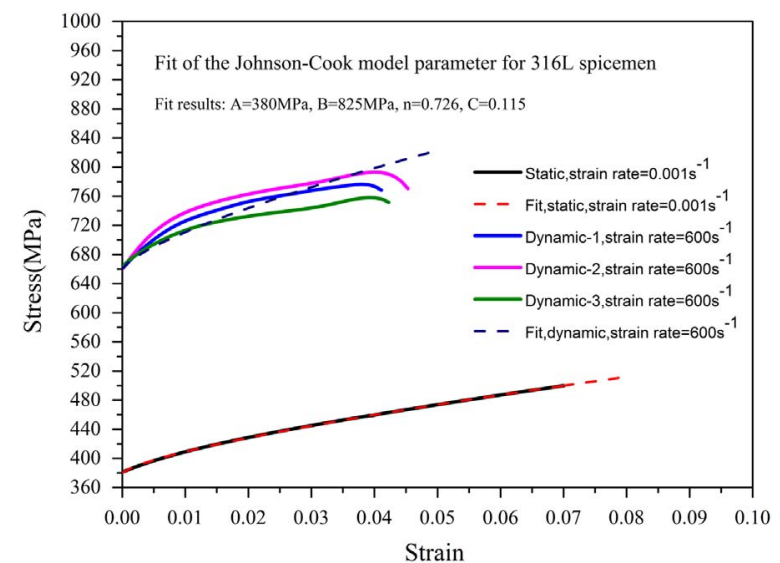

Fig. 4. Dynamic and quasi-static stress-strain curves of SLM printed 316L stainless steel specimens and fitting results for Johnson-Cook constitutive model.

starts to degrade, as shown in Fig. 8.

$\varepsilon_{0}^{p l}=\left[D_{1}+D_{2} \exp \left(-D_{3}\right)\right]\left(1+D_{4} \ln \dot{\epsilon}^{*}\right)\left(1+D_{5} T^{*}\right)$

In Eq. (2), D1-D5 are damage parameters, and the second and third brackets consider the strain rate effect and temperature effect, respectively. is the stress triaxility, which refers to hydrostatic pressure to Mises equivalent stress. The damage initiation parameter D1 is set as
0.2 (D2-D5 are set as zero), stress triaxiality effect, strain rate effect and temperature effect are not considered here.

The damage evolution criterion (shown in Fig. 8), which describes the degradation of the material stiffness and the element failure and removal after damage initiation, was chosen as the "linear displacement criterion". The stiffness decreases linearly after damage initiation until the failure of element when the effective plastic displacement of the element reaches the failure value of $u_{f}^{p l}=0.025$. Before damage initiation, $\dot{\bar{u}}^{p l}=0$, and after damage initiation, the effective displacement $\bar{u}^{p l}$ is defined with the evolution equation $\dot{\bar{u}}^{p l}=L \dot{\bar{\varepsilon}}^{p l}$, where $\mathrm{L}$ is the characteristic length of the element and $\dot{\bar{\varepsilon}}^{p l}$ is the plastic strain rate of the element. The detailed explanation of damage initiation and the damage evolution criteria can be found in Abaqus user's manual [57]. The material parameters used in the model are listed in Table 2.

In Fig. $8, \sigma_{y 0}$ and $\bar{\varepsilon}_{0}^{p l}$ are the yield stress and the equivalent plastic strain at the onset of damage and $\bar{\varepsilon}_{f}^{p l}$ is the equivalent plastic strain at failure. The material stiffness decreases linearly with the damage variable $\mathrm{D}$ increasing from 0 to 1 . The damage variable $\mathrm{D}$ increases according to $\dot{\mathrm{D}}=\frac{\dot{\vec{t}} p l}{u_{f}^{p l}}$. When $\mathrm{D}$ reaches the value of 1 , the element fails and is deleted from the mesh. The fracture of the structure will occur when a number of elements fail. 
(a)

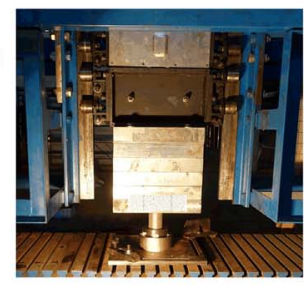

(b)

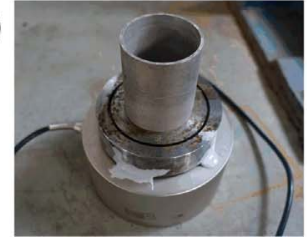

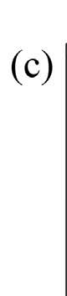

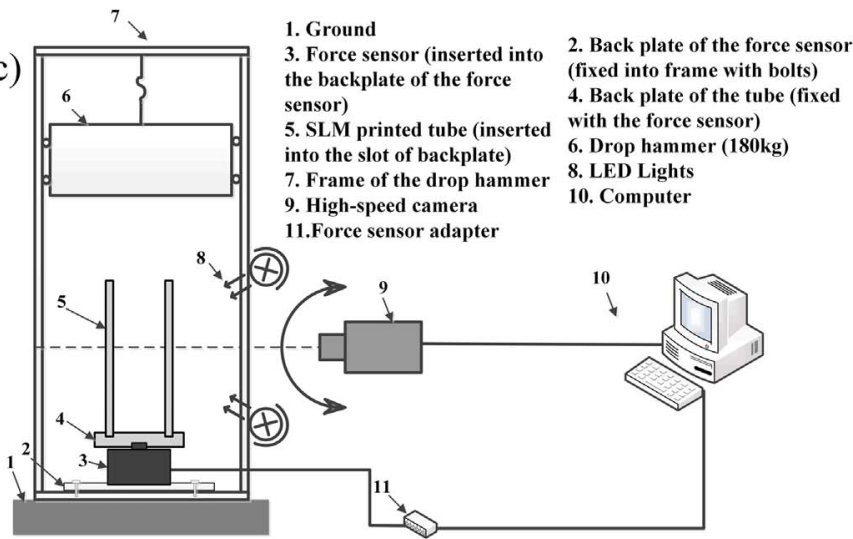

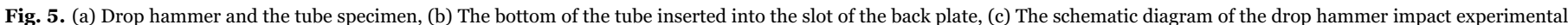
setup.

\section{Results and discussion}

Fig. 9 shows good agreement between the experimental and numerical results of the drop hammer displacement-time and velocity-time curves during the crushing stage. The velocity of the hammer decreases from $7.4 \mathrm{~m} / \mathrm{s}$ to $2.2 \mathrm{~m} / \mathrm{s}$ progressively before the tube is fully crushed. The maximum displacement reaches $60 \mathrm{~mm}$ when tube compaction occurs, that is, the stroke efficiency of the SLM printed tube is approximately $85.7 \%$, higher than the classical tube folding (70-80\%) and tube splitting (about 80\%) [58]. This high stroke efficiency is a result of the mixture mode of buckling and splitting, the upper buckled section fractures and inserts into the cavity of the lower undeformed section. This fractured section performs as a shaped die to initiate the following splitting process [34-39]. Then, the lower section experiences a splitting process with the expansion and splitting of the tube wall. This whole process will be illustrated in detail in the following paragraphs.

Fig. 10 shows the experimental and numerical results of the crushing process of the SLM 3D printed tube. Fig. 11 shows the crushing force-displacement curve of the tube: this curve has two peaks in the first stage (buckling stage) and two peaks in the second stage (splitting stage). The first stage is a typical buckling process, having force-displacement curve with force peaks and valleys [17,56], each peak in this stage corresponds to a fold formation, and each valley corresponds to the fracture of the fold region. The second stage is a splitting process, having a long stroke and a steady crushing force $[34,36]$.

As shown in Fig. 10-Image (2), the first axisymmetric fold initiates at the first internal groove region, as the first internal groove has the

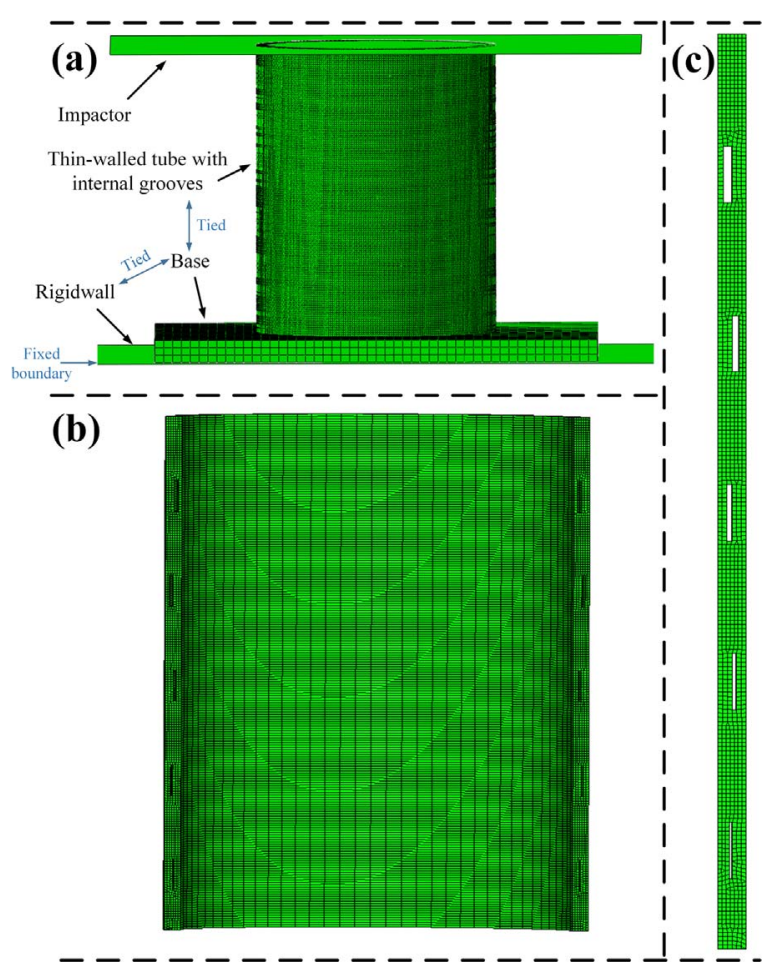

Fig. 7. Numerical model (a) Four parts in the numerical model (b) Cross section of the tube (c) Mesh details on the tube wall.

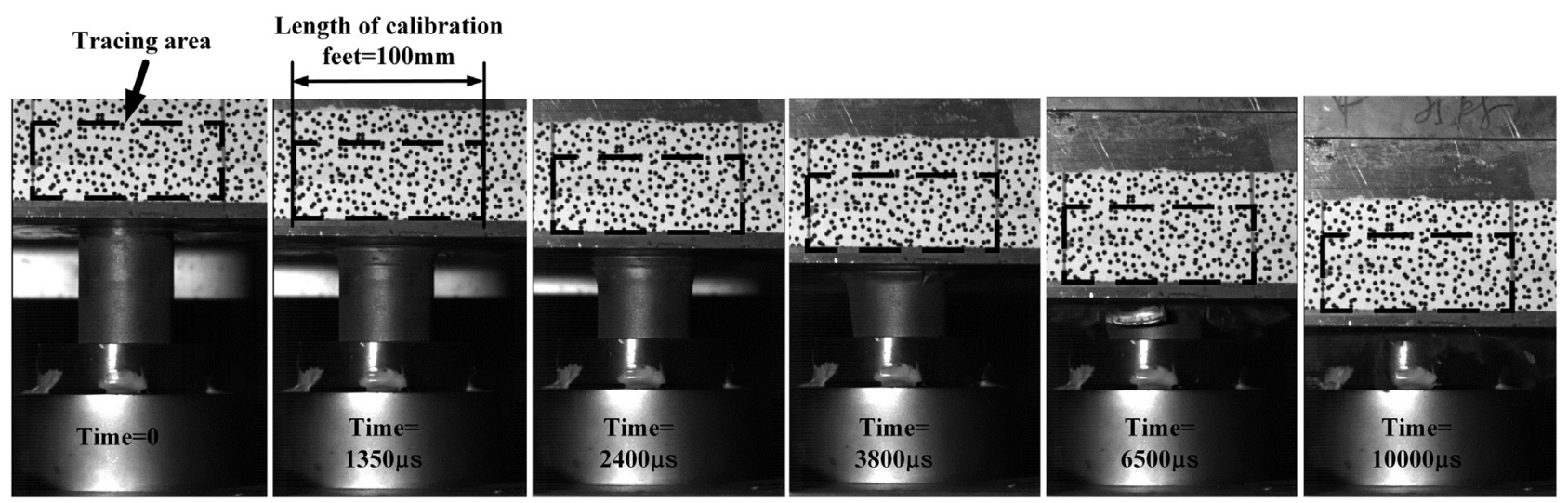

Fig. 6. Images of the crushing process captured by high-speed camera. 


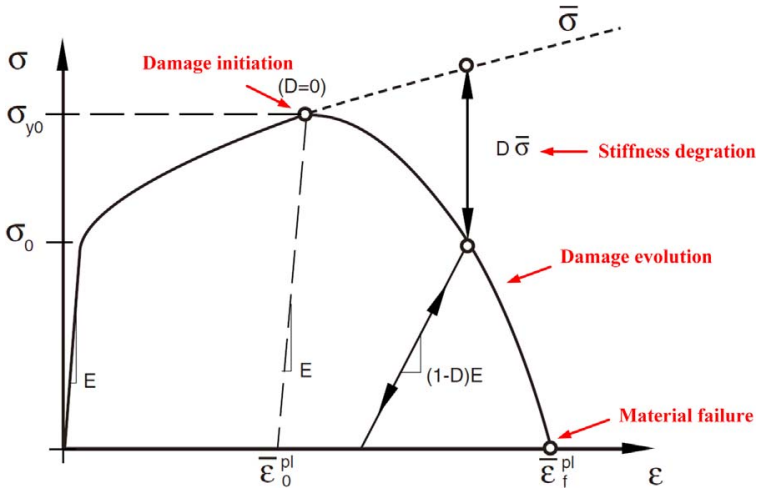

Fig. 8. Stress-strain curve with progressive damage degradation [57].

Table 2

Material parameters for each part in the numerical model.

\begin{tabular}{|c|c|c|c|c|c|c|}
\hline Parts & Material & $\begin{array}{l}\text { Constitutive } \\
\text { model }\end{array}$ & $\mathrm{E}(\mathrm{GPa})$ & $\begin{array}{l}\rho \\
(\mathrm{kg} / \\
\left.\mathrm{m}^{3}\right)\end{array}$ & $\mu$ & Remarks \\
\hline Impactor & I & $\begin{array}{l}\text { Analytical } \\
\text { Rigid }\end{array}$ & I & / & / & $\begin{array}{l}\text { Mass }=180 \mathrm{~kg} \\
\mathrm{~V}=7.4 \mathrm{~m} / \mathrm{s}\end{array}$ \\
\hline Tube & $\begin{array}{l}\text { SLM } \\
\text { printed } \\
316 \mathrm{~L} \\
\text { stainless } \\
\text { steel }\end{array}$ & $\begin{array}{l}\text { Johnson- } \\
\text { Cook }\end{array}$ & 200 & 7830 & 0.3 & $\begin{array}{l}\text { Johnson-Cook } \\
\text { damage } \\
\text { initiation } \\
\text { D1=0.2, D2- } \\
\text { D5=0; Damage } \\
\text { evolution: } \\
u_{f}^{p l}=0.025\end{array}$ \\
\hline Base & Steel & Elastic & 210 & 7800 & 0.3 & \\
\hline Rigid wall & I & $\begin{array}{l}\text { Analytical } \\
\text { Rigid }\end{array}$ & / & / & / & $\begin{array}{l}\text { All freedoms } \\
\text { fixed }\end{array}$ \\
\hline
\end{tabular}

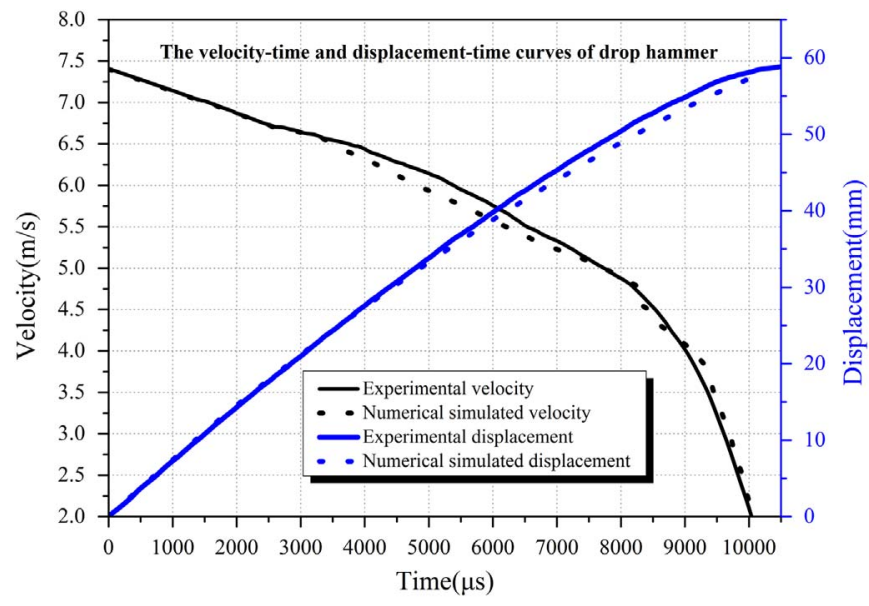

Fig. 9. Drop hammer velocity-time and displacement-time curves.

deepest defect, performing as a trigger $[26,50,59,60]$. The first internal groove can control the buckling position and buckling mode, which is the same as we predict according to the "proactive regulation theory by gradient grooves" in our previous work [51]. However, the first fold cannot be fully bent into a complete fold before fracture occurs in the groove region along the whole circumferential hoop, as shown in Fig. 10-Image (3). This fracture phenomenon differs from the typical progressive buckling behavior of the thin-walled metal tube $[16,17,20,25]$, as the SLM printed material brittleness character plays a key role.

Then, the top fractured region slides down into the cavity of the bottom tube before the hammer accesses the bottom tube structure. The crushing force in Fig. 11 drops from the peak (2) to valleys (4) and
(5) during the first fold fracture and sliding process. Valley (4) is about zero as the complete fracture of the first fold. The second fold starts to form when the hammer accesses the tube again, as shown in Image (6), corresponding to force peak (6); the fold bends in the second groove region before the fracture occurs; and then, the second fractured ring slides down together with the first ring into the cavity of the tube. The force decreases from the peak (6) to the valley (7), and then, the buckling stage starts to transform to the splitting stage as the two fold rings, performing as a "shaped die" [34-36,39], expand the tube wall to a cracking limit.

The hammer compresses the "shaped die" downward into the undeformed tube continuously to promote the splitting process. Longitudinal cracks initiate and develop along the tube length in the splitting process (Images (10)-(14)), the same as typical splitting process [34-39]. The force peaks in the splitting stage are relatively lower than the buckling stage; however, there is no sudden drop of the force as the splitting and the curling process is more stable than the buckling and circumferential fractures in the buckling stage. The flat force character of the splitting mode compared with the oscillation character of the buckling mode was first analyzed by Reddy and Reid [34], they found the main advantage of the splitting mode: long stroke and steady crushing force. As this SLM printed tube can experience the two modes during the crushing process, both the advantages of the two modes can be taken in one structure. The tube is completely compacted in Image (14), the final crush morphology of the experimental and numerical results are shown in Images (15) and (16) in Fig. 10.

As the results show, the internal grooves can affect the buckling and fracture positions during the buckling stage, but have little effect on the splitting position during the splitting stage. In contrast to the ideal dynamic progressive buckling process regulated by gradient grooves in the wrought steel tubes [51], the SLM printed material brittleness plays an important role in the crushing process of the printed tube. In the buckling stage, the two folds both initiate on the location of the internal grooves, but due to the brittleness of the material, the incomplete folds fracture on the location of the grooves and slide downward into the cavity of the tube. In the splitting stage, as radial cracks form and the splitting and curling of the tube wall develop along the tube length, the internal grooves do not play a major role.

The deepest internal groove (on the top) can initiate the buckling process and control the first force peak to $150 \mathrm{kN}$, as shown in the experimental results. The energy absorption curve is shown in Fig. 12. The total energy absorption and displacement before compaction of the tube are approximately $4500 \mathrm{~J}$ and $55 \mathrm{~mm}$ respectively, and the energy absorbed per length (the mean crushing force) is $81 \mathrm{kN}$. The ratio of the peak force and the mean force is 1.85 , lower than that of the typical perfect tube [61], revealing the trigger effect of the first internal groove.

The specific energy absorption (SEA) of this printed tube is $25 \mathrm{~kJ} /$ $\mathrm{kg}$, which is slightly lower than typical perfect crushing tube $(30 \mathrm{~kJ} / \mathrm{kg})$ and typical splitting and curling tube $(45 \mathrm{~kJ} / \mathrm{kg})$ [58]. As Fig. 12 shows, the energy absorption of the buckling stage and splitting stage are approximately $1500 \mathrm{~J}$ and $3000 \mathrm{~J}$ respectively, and the displacement of the two stages are $21 \mathrm{~mm}$ and $34 \mathrm{~mm}$ respectively. The average crushing force for the two stages are $71 \mathrm{kN}$ and $88 \mathrm{kN}$ respectively. So in this tube, the splitting process absorbs more energy and performs more efficient than the buckling process, because the buckling folds are not complete before fracture. Overall, the buckling-splitting crushing mode of the SLM printed tube, as a double stage mode in one simple structure, with a high stroke efficiency, provides a new energy absorption approach for engineering application.

\section{Conclusions}

1. Quasi-static and dynamic compression tests have been performed on the SLM printed 316L stainless steel. The Johnson-Cook constitutive model parameters are fitted from the experimental data;

2. Drop hammer experiment and numerical simulation have been 


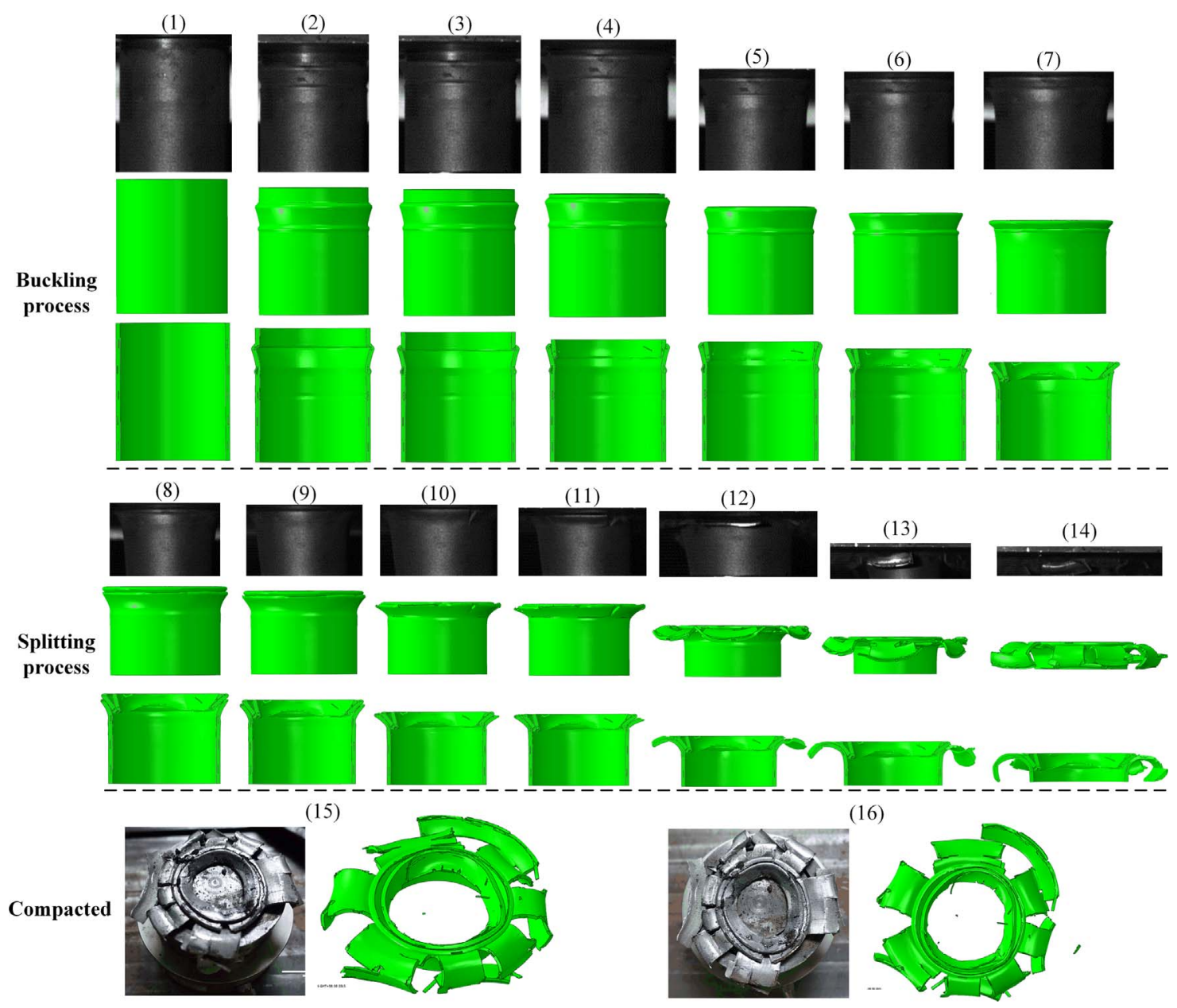

Fig. 10. Comparison of experimental and numerical results of crushing process and compacted morphology.

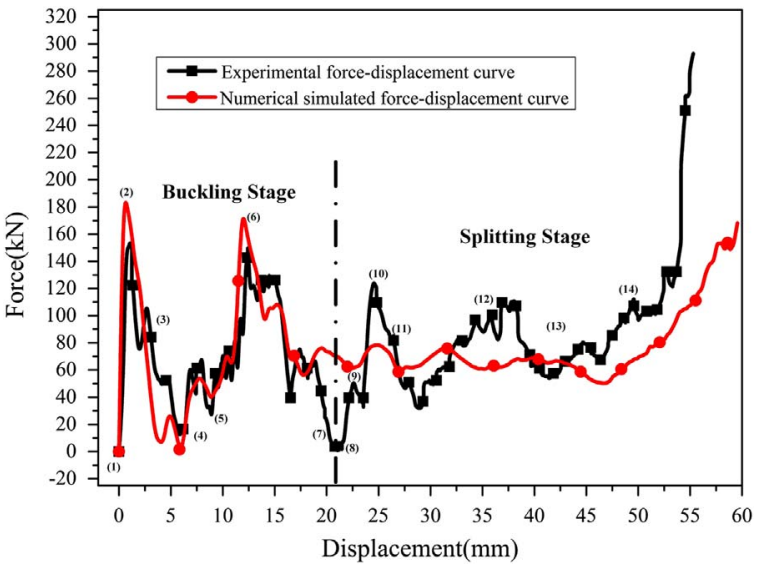

Fig. 11. Experimental and numerical crushing force-displacement curves.

performed to study the crushing behavior of the SLM printed $316 \mathrm{~L}$ stainless steel tube with internal defects. The buckling-splitting behavior is obtained from the experimental and numerical results. The internal grooves can control the initial buckling position and structure fracture position during the buckling stage.

3. The experimental and numerical force-displacement curves can reflect the buckling-splitting process. The ratio of the peak force and the mean force is lower than that of the typical perfect tube as the groove triggering effect. The long stroke efficiency is an advantage of this special buckling-splitting mode. The energy absorption capacity and efficiency of the splitting stage is higher

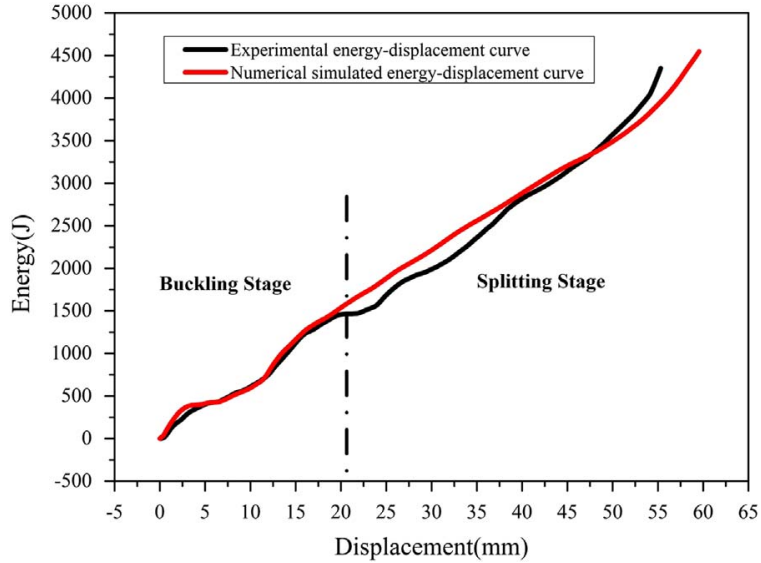

Fig. 12. Experimental and numerical energy absorption-displacement curves.

than the buckling stage. The buckling-splitting crushing mode of the SLM printed tube, as a double stage mode in one simple structure, with a high stroke efficiency, provides a new energy absorption approach for engineering application.

\section{References}

[1] H. Lipson, M. Kurman, Fabricated: The New World of 3D Printing, John Wiley \& Sons, 2013.

[2] G.N. Levy, R. Schindel, J.P. Kruth, Rapid manufacturing and rapid tooling with layer manufacturing (Lm) technologies, state of the art and future perspectives, CIRP Ann. - Manuf. Technol. 52 (2) (2003) 589-609. 
[3] D. Gu, Y.-C. Hagedorn, W. Meiners, G. Meng, R.J.S. Batista, K. Wissenbach, R. Poprawe, Densification behavior, microstructure evolution, and wear performance of selective laser melting processed commercially pure titanium, Acta Mater. 60 (9) (2012) 3849-3860..

[4] S. Leuders, M. Thöne, A. Riemer, T. Niendorf, T. Tröster, H.A. Richard, H.J. Maier, On the mechanical behaviour of titanium alloy TiAl6V4 manufactured by selective laser melting: fatigue resistance and crack growth performance, Int. J. Fatigue 48 (2013) 300-307..

[5] E. Yasa, J.P. Kruth, Microstructural investigation of Selective Laser Melting 316L stainless steel parts exposed to laser re-melting, Proc. Eng. 19 (2011) 389-395.

[6] V.J. Challis, X. Xu, L.C. Zhang, A.P. Roberts, J.F. Grotowski, T.B. Sercombe, High specific strength and stiffness structures produced using selective laser melting, Mater. Des. 63 (2014) 783-788.

[7] C. Yan, L. Hao, A. Hussein, P. Young, D. Raymont, Advanced lightweight 316L stainless steel cellular lattice structures fabricated via selective laser melting, Mater. Des. 55 (2014) 533-541..

[8] J. Sun, Y. Yang, D. Wang, Mechanical properties of a Ti6Al4V porous structure produced by selective laser melting, Mater. Des. 49 (2013) 545-552..

[9] A. Hussein, L. Hao, C. Yan, R. Everson, P. Young, Advanced lattice support structures for metal additive manufacturing, J. Mater. Process. Technol. 213 (7) (2013) 1019-1026.

[10] S. McKown, Y. Shen, W.K. Brookes, C.J. Sutcliffe, W.J. Cantwell, G.S. Langdon, G.N. Nurick, M.D. Theobald, The quasi-static and blast loading response of lattice structures, Int. J. Impact Eng. 35 (8) (2008) 795-810.

[11] S. Tsopanos, R.A.W. Mines, S. McKown, Y. Shen, W.J. Cantwell, W. Brooks, C.J. Sutcliffe, The influence of processing parameters on the mechanical properties of selectively laser melted stainless steel microlattice structures, J. Manuf. Sci. Eng. 132 (4) (2010) 041011..

[12] Y. Shen, W.J. Cantwell, R.A.W. Mines, K. Ushijima, The properties of lattice structures manufactured using selective laser melting, Adv. Mater. Res. 445 (2012) $386-391 .$.

[13] M. Smith, Z. Guan, W.J. Cantwell, Finite element modelling of the compressive response of lattice structures manufactured using the selective laser melting technique, Int. J. Mech. Sci. 67 (2013) 28-41..

[14] S. Merkt, C. Hinke, J. Bültmann, M. Brandt, Y.M. Xie, Mechanical response of TiAl6V4 lattice structures manufactured by selective laser melting in quasistatic and dynamic compression tests, J. Laser Appl. 27 (S1) (2015) S17006..

[15] K. Yang, S. Xu, J. Shen, S. Zhou, Y.M. Xie, Energy absorption of thin-walled tubes with pre-folded origami patterns: numerical simulation and experimental verification, Thin-Walled Struct. 103 (2016) 33-44..

[16] A.G. Olabi, E. Morris, M.S.J. Hashmi, Metallic tube type energy absorbers: a synopsis, Thin-Walled Struct. 45 (7-8) (2007) 706-726.

[17] A.A.A. Alghamdi, Collapsible impact energy absorbers: an overview, Thin-Walled Struct. 29 (2001) 189-213..

[18] G. Lu, T. Yu, Energy Absorption of Structures and Materials, Elsevier, 2003.

[19] N. Jones, Structural Impact, Cambridge university press, 2011.

[20] W. Abramowicz, N. Jones, Dynamic progressive buckling of circular and square tubes, Int. J. Impact Eng. 4 (4) (1986) 243-270..

[21] N.K. Gupta, R. Velmurugan, An analysis of axi-symmetric axial collapse of round tubes, Thin-Walled Struct. 22 (4) (1995) 261-274..

[22] D. Karagiozova, N. Jones, Dynamic elastic-plastic buckling of circular cylindrical shells under axial impact, Int. J. Solids Struct. (2000) 2005-2034..

[23] D. Karagiozova, N. Jones, On dynamic buckling phenomena in axially loaded elastic-plastic cylindrical shells, Int. J. Non-Linear Mech. 37 (2002) 1223-1238..

[24] F.C. Bardi, H.D. Yun, S. Kyriakides, On the axisymmetric progressive crushing of circular tubes under axial compression, Int. J. Solids Struct. 40 (12) (2003) 3137-3155..

[25] N.K. Gupta, Venkatesh, A study of the influence of diameter and wall thickness of cylindrical tubes on their axial collapse, Thin-Walled Struct. 44 (3) (2006) 290-300..

[26] X.W. Zhang, Q.D. Tian, T.X. Yu, Axial crushing of circular tubes with buckling initiators, Thin-Walled Struct. 47 (6-7) (2009) 788-797.

[27] H. Al-Qureshi, Mechanics of static and dynamic inversion processes, Int. J. Mech. Sci. 39 (2) (1997) 147-161..

[28] S. Reid, J. Harrigan, Transient effects in the quasi-static and dynamic internal inversion and nosing of metal tubes, Int. J. Mech. Sci. 40 (2) (1998) 263-280.

[29] X. Qiu, L. He, J. Gu, X. Yu, A three-dimensional model of circular tube under quasistatic external free inversion, Int. J. Mech. Sci. 75 (2013) 87-93..

[30] X. Yu, X. Qiu, T.X. Yu, Analysis of the free external inversion of circular tubes based on deformation theory, Int. J. Mech. Sci. 100 (2015) 262-268.

[31] A.A.N. Aljawi, A.A.A. Alghamdi, T.M.N. Abu-Mansour, M. Akyurt, Inward inversion of capped-end frusta as impact energy absorbers, Thin-Walled Struct. 43 (4) (2005) 647-664..

[32] O. Mohammadiha, H. Ghariblu, Crush response of variable thickness distribution inversion tubes under oblique loading, Thin-Walled Struct. 109 (2016) 159-173.

[33] X. Qiu, X. Yu, Y. Li, T.X. Yu, The deformation mechanism analysis of a circular tube under free inversion, Thin-Walled Struct. 107 (2016) 49-56..

[34] T.Y. Reddy, S.R. Reid, Axial splitting of circular metal tubes, Int. J. Mech. Sci. 28 (2) (1986) 111-131..

[35] G. Lu, L.S. Ong, B. Wang, H.W. Ng, An experimental study on tearing energy in splitting square metal tubes, Int. J. Mech. Sci. 36 (12) (1994) 1087-1097.

[36] X. Huang, G. Lu, T.X. Yu, On the axial splitting and curling of circular metal tubes, Int. J. Mech. Sci. 44 (11) (2002) 2369-2391.

[37] P. Jiang, W. Wang, G.J. Zhang, Size effects in the axial tearing of circular tubes during quasi-static and impact loadings, Int. J. Impact Eng. 32 (12) (2006) 2048-2065.

[38] J. Li, G. Gao, H. Dong, S. Xie, W. Guan, Study on the energy absorption of the expanding-splitting circular tube by experimental investigations and numerical simulations, Thin-Walled Struct. 103 (2016) 105-114..

[39] J. Rouzegar, M. Karimi, Numerical and experimental study of axial splitting of circular tubular structures, Thin-Walled Struct. 105 (2016) 57-70..

[40] J.A. DeRuntz, P. Hodge, Crushing of a tube between rigid plates, J. Appl. Mech. 30 (3) (1963) 391-395..

[41] N.K. Gupta, G.S. Sekhon, P.K. Gupta, Study of lateral compression of round metallic tubes, Thin-Walled Struct. 43 (6) (2005) 895-922.

[42] T.Y. Reddy, S. Reid, Lateral compression of tubes and tube-systems with side constraints, Int. J. Mech. Sci. 21 (3) (1979) 187-199..

[43] A. Baroutaji, M. Gilchrist, D. Smyth, A. Olabi, Crush analysis and multi-objective optimization design for circular tube under quasi-static lateral loading, ThinWalled Struct. 86 (2015) 121-131..

[44] A. Baroutaji, M.D. Gilchrist, A.G. Olabi, Quasi-static, impact and energy absorption of internally nested tubes subjected to lateral loading, Thin-Walled Struct. 98 (2016) 337-350.

[45] A. Baroutaji, E. Morris, A.G. Olabi, Quasi-static response and multi-objective crashworthiness optimization of oblong tube under lateral loading, Thin-Walled Struct. 82 (2014) 262-277..

[46] S. Reid, W. Bell, Influence of strain hardening on the deformation of thin rings subjected to opposed concentrated loads, Int. J. Solids Struct. 18 (8) (1982) 643-658..

[47] G. Lu, A study of the crushing of tubes by two indenters, Int. J. Mech. Sci. 35 (3) (1993) 267-278..

[48] K. Liu, K. Zhao, Z. Gao, T. Yu, Dynamic behavior of ring systems subjected to pulse loading, Int. J. Impact Eng. 31 (10) (2005) 1209-1222.

[49] S.C.K. Yuen, G.N. Nurick, The energy-absorbing characteristics of tubular structures with geometric and material modifications: an overview, Appl. Mech. Rev. 61 (2) (2008) 020802..

[50] A. Alavi Nia, K. Fallah Nejad, H. Badnava, H.R. Farhoudi, Effects of buckling initiators on mechanical behavior of thin-walled square tubes subjected to oblique loading, Thin-Walled Struct. 59 (2012) 87-96.

[51] Y. Wei, Z. Yang, H. Yan, Y. Guo, X. Wu, C. Huang, Proactive regulation of axial crushing behavior of thin-walled circular tube by gradient grooves, Int. J. Mech. Sci. 108-109 (2016) 49-60.

[52] I. Tolosa, F. Garciandía, F. Zubiri, F. Zapirain, A. Esnaola, Study of mechanical properties of AISI 316 stainless steel processed by "selective laser melting", following different manufacturing strategies, Int. J. Adv. Manuf. Technol. 51 (5-8) (2010) 639-647.

[53] F.G. Bachmann, O. Rehme, C. Emmelmann, W. Hoving, Y. Lu, K. Washio, Rapid manufacturing of lattice structures with selective laser melting, 6107 (2006) 61070K-61070K-12.

[54] J.M. ALEXANDER, An approximate analysis of the collapse of thin cylindrical shells under axial loading, Q. J. Mech. Appl. Math. 13 (1) (1960) 10-15.

[55] G.R. Johnson, W.H. Cook, Fracture characteristics of three metals subjected to various strains, strain rates, temperatures and pressures, Eng. Fract. Mech. 21 (1) (1985) 31-48..

[56] A.A. Singace, H. Elsobky, T.Y. Reddy, On the eccentricity factor in the progressive crushing of tubes, Int. J. Solids Struct. 32 (24) (1995) 3589-3602..

[57] Hibbitt, Karlsson, Sorensen, ABAQUS/Explicit: User's Manual, Hibbitt, Karlsson and Sorenson, 2001.

[58] A.A. Ezra, An Assessment of Energy Absorbing Devices for Prospective Use in Aircraft Impact Situations, Dynamic Response of Structures, Pergamon Press, 1972, pp. 225-226.

[59] X.W. Zhang, H. Su, T.X. Yu, Energy absorption of an axially crushed square tube with a buckling initiator, Int. J. Impact Eng. 36 (3) (2009) 402-417.

[60] S. Lee, C. Hahn, M. Rhee, J.-E. Oh, Effect of triggering on the energy absorption capacity of axially compressed aluminum tubes, Mater. Des. 20 (1) (1999) 31-40.

[61] A. Andronicou, A.C. Walker, A plastic collapse mechanism for cylinders under uniaxial end compression, J. Constr. Steel Res. 1 (4) (1981) 23-34.. 